\title{
Relevance of youth representation through political proportions in Uganda
}

\author{
David Mwesigwa ${ }^{1 *}$, Khalid Abdul Wahid ${ }^{2}$ \\ Department of Public Administration and Management, Faculty of Management Sciences, Lira \\ University - Mid-north of Uganda ${ }^{1 *}$ \\ Faculty of Information Management, Universiti Teknologi MARA Kelantan Branch, Malaysia ${ }^{2}$ \\ $\underline{\text { mwesigwadavid22@gmail.com }}^{1^{*}}$, awkhalid@uitm.edu.my ${ }^{2}$
}

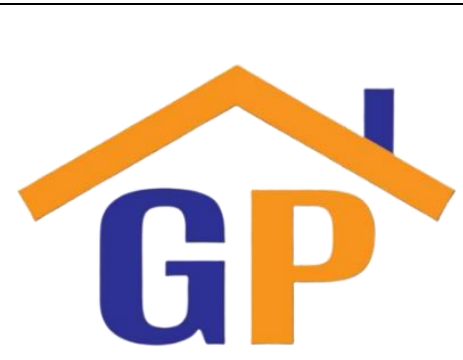

Article History

Received on 11 December 2020... Revised on 1 January 2021

Accepted on 8 January 2021

\begin{abstract}
Purpose: This study discusses the relevance of proportions of youth representatives in the governance of Uganda

Research methodology: The central approach for this article was a desk review of obtainable works on youth representation in Uganda and other parts of the world
\end{abstract}

Results: The outcomes suggest that the political interests considered as youth interests remain a big challenge and are hard to separate from other interests and are often considered public interests. As a consequence, proportions are one of the means to reimbursing for obstacles against the youths (and other marginalised groups) as well as an incentive towards their role in both politics and the national economy, which aim to achieve a degree of age-based parity in political statistics and as an element of democratisation processes. Thus, considering this method in relation to representational and expressive representatives who symbolise a unique constituency is necessary.

Limitations: This study's main limitation is that much of the issues raised are limited to Uganda and may not be generalized across other countries with different political environments. Contribution: This study is relevant to Public Administration and political science seeing that youth functional roles remain loose in poise since what is represented is reliant on diverse stakeholders whose interests are not static.

Keywords: Youth, Representation, Political proportion, Democracy

How to cite: Mwesigwa, D., \& Wahid, K. A. (2021). Relevance of youth representation through political proportions in Uganda. Journal of Governance and Accountability Studies, 1(1), 29-41.

\section{Introduction}

The age-based proportions method differs worldwide; from compulsory seats in parliamentary assemblies, boards, Local Government Councils (LGCs), political parties to charity organisations. Dahlerup (2005) recognises two forms of democratic age-based proportions, viz., reserved seats and candidate proportions. Reserved seats are a form of proportion, which by law, a certain number of seats for a particular electorate is specified. In Uganda, particular electorates in this group are; the youths, women, persons with disabilities (PWDs), the workers and the army (Goodfellow, 2017:1570). A small proportion of candidates for election is stated regarding candidate proportions, and every political party list is mandated to obey. This form of proportion can be set in the national Constitution, subsidiary legislations and or rules governing individual political parties. Nevertheless, in other cases, political parties might espouse a voluntary proportion method minus any law. Dahlerup (2005:142) states that proportions can be gender-based or age-based in which an upper limit for either sex or age group is fixed for candidates on party lists. Okedele (2020) notes that whereas every type of proportion seems to be worldwide, reserved seats are famous to Africa in the form of affirmative action and national parliamentary Proportions Are More Prominent In Africa And South America. 
Reserved Seats Are Visible in the National Parliament and Local Government council (LGC) politics in Uganda where one-third of all seats are reserved for women in proportion to the number of party seats (Kadaga, 2013:32) and so are other groups such as the youths.

The rationale behind political proportions is that they have been appreciated as a political measure in a number of nations trying to cure political limitations that specific electorates suffered in the winnertakes-it-all electoral system (Bieber \& Wingerter, 2020). It is recognised that choice of political aspirants has often disadvantaged certain groups, mainly the youths, women and PWDs' rise to political influence in comparable statistics. Obtainable literature describes the consequences associated to socio-cultural-economic as well as political organisations such as democratic structures and ideology of a political party on recruitment of the youths, women and PWDs into political spaces (Franzmann, 2019:332). Studies consider age-based proportions to attract legitimacy from the plight of youth under representation attributable to discriminatory practices of political parties and the government as a whole (Weinmann \& Grotz, 2020). Proportions are thus presented as key in raising representation in openly elected institutions such as Parliaments and LGCs.

There are several benefits ensuing from the adoption of youth proportions, they include: recompense for concrete obstacles thwarting the youth from achieving a reasonable portion in political spaces, reducing limitations of symbolic youth in institutions; guaranteeing an age-based stable political authority that involves youth aspirations and interests, facilitating critical discussions and building coalitions across boundaries for a common purpose (Kassman \& Vamstad, 2019:485). These strategies are believed to consolidate young people in energising essential changes in systems of governance, changes in power-sharing as well as economic prospects. While these benefits are likely to follow a normative version of youths' historical isolation, comparable opinions on the introduction of the YPPs focuses on youth involvement, political parity, the political leaders, strategic objectives as well as the method of transferring international norms. I have suggested, in this article, that political proportions are: (i) a consequence of youths' struggles to rally more youths for political representation; (ii) Applied by political parties owing to the transmissible outcome and are incorporated by political leaders for consolidating influence over party legislatures and political pessimists; (iii) a key influence to the normative philosophies of parity and representation with assertions of justice and democratic processes; and (iv) predisposed by trans-national actors and systems using information distribution and online crusades.

However, assertions on age-based proportions have encountered censures from pessimists who note that in fulfilment of parity, the optimists favour certain groups against the men and the women (hereafter called others); by giving favour to the youths, administrations and political parties which become one-sided and nondemocratic. Consequently, the pessimists look at proportions as unfair since they reduce preferences available to the voter since the set from which to choose is restricted, which forbids capable contenders. When enacted into law, the pessimists look at proportions as meddling in party administration and interests upon which community groups are superimposed is important to note. The proponents are perceived as aiding individual group rivalry with respect to material gains. In the earlier proportion report sequence on African performance, it can be observed that: when we take the genuine omission of the youth $\mathrm{s}$ as the initial idea, i.e., when we appreciate that several complications thwart the youths from joining the arena of policymaking, then proportions are not understood as favouring to others, but as recompense for every hindrance that the youths encounter. When all these obstacles are detached, proportions will no longer be essential. In this case, proportions become transitory. It may take years, yet, before every societal, traditional and partisan obstacle thwarting balanced representation is eliminated. This opinion emphasises that there are obstacles and there is a necessity for recompense with regard to age-based proportions suggestive of issues of parity and justice.

By appreciating the progressive approach of proportions, academics ease the pressures projected of the age-based disparities in disrespect of the others' category, which can be controlled by governments and political parties. At any rate, statistics express the nature of representatives - the age-based rationality concerning the features of representatives. There is, as a consequence, an 
incomplete signal of relegation of others' regarding their functional roles. In this view, we can observe age-based proportions as a defence for expressive and representative standing for representation. This opinion is line with such assertions that present proportions as being espoused for political schemes of leaders and parties or as a world-wide style based on universal standards. Nevertheless, the degree to which we can regulate proportion representatives to this form of illustration is a subject of discussion seeing ideas favouring the critical mass theory which advocate that critical communities may turn to critical actions.

Whereas the YPPs are glorified, the pessimists maintain that they accomplish little in reducing existing disproportions in political situations. Lebon, Baujard, Gavrel, Igersheim \& Laslier (2018) state that proportion system is not satisfactory to enhance youth involvement if a host of organisations such as political parties and the civil society do not take ingenuity of encouraging the youth in their individual structures. The challenge of such favourable actions is that it has been reverberated by other scholars such as Lebon et al (2018) who have reservations about the efforts to reorganise obtainable openings in the structures of the prevailing socio-political arrangements. Essentially, we can perceive such endeavours as preserving the situation of organisational dissection and methods of sharing prospects; whilst it may be possible to favour such favourable engagements as a solitary strategy, an opinion that can attain little if they function free from rules focused at reducing gaps in affluence, position and influence. These opinions tend to emphasise the worth of socio-cultural, socioeconomic and socio-political obstacles acknowledged previously. As a result, the pessimists appear not to challenge the procedure of YPPs instead to advocate extra policies for making them more operative.

\section{Literature review and hypothesis development}

\subsection{Proportions on the Ugandan political scene}

In Uganda, political proportions were formed in respect of the absence of specific categories in direct public affairs. At the beginning, the youths had no single seat as they were perceived to be too young to take part in policy making processes, however, their significance, as a unique category, was acknowledged with only one seat countrywide (Mugisha, Ojok, Kiranda \& Kabasa, 2016:55). This was later extended to cover each of the four regions of Uganda plus one national female representative in the national assembly since 2006. This was attained after the Constitution of Uganda was promulgated in 1995. While the success does not balance with the women who attained a seat representing each of the districts as well as the one-third minimum representation in the LGCs amongst other proportions for special interest groups, it was a landmark in itself (Government of Uganda, 1995; Government of Uganda, 1997). This affirmative act was intended to correct the historical biases of relegating the youths from every prospect of decision making. The political confirmation was thus enhanced with an additional provision which permitted anyone aged 18 to compete for any political office, except that of President, which was capped at a minimum of 35 years.

The two achievements, highlighted above, exposed the youths and empowered them to contribute to policymaking fora albeit in decimal numbers. Also, the government of Uganda introduced the legal provision for youth involvement in political affairs both at the national legislature as well as every LGC in the country. As an evolutionary step, the democratic principles of the Uganda Constitution state that: (i) the state shall be based on democratic principles which empower and encourage the active participation of all citizens at all levels in their own governance, and (ii) all the people of Uganda shall have access to leadership positions at all levels, subject to the Constitution. (Government of Uganda, 1995). As a step and as a matter of political proportion, the legislators who introduced Uganda YPPs anticipated that exclusion of specific groups in politics would be counterbalanced in the medium-term. In effect, Otite and Ohwona (2020:183) state that the political role of the youths is changing across nations. As a consequence, after more than a decade of YPP, the constitutional reviews have embraced the YPP and those of other previously underprivileged groups thus upholding that special interest groups as essential constituents both in parliament and LGCs. The assessors appreciate that democratic polls remain tricky for such constituents and, as a result, political 
proportions should remain as a redeemer. To date, constant discussions advocate that the YPP be raised to ten representatives.

\subsection{The Youth Political Proportions (YPPs) in Uganda}

Diverse descriptions have been put forward by a number of scholars and or writers concerning the connotation of youths from international organisations to national organisations. According to the United Nations (UN), the youths should be set apart from other groups of society using the basis of age. Accordingly, the UN labels the youths as a person between 15 and 24 years. While the definition of youths varies across nations, the Uganda Constitution (1995) identifies the youths as any person aged 18 but not older than 30 years. In their study, Otite and Ohwona (2010:183) reveals that 20\% of the global population are youths. Also, Mwesigwa and Mubangizi (2019:56) found that the universal population of the youths is approximately 1.8billion (25\% of humankind); majority of whom (about $90 \%$ ) living in the third-world nations and one-third (more than 30\%) in Commonwealth Nations. In Africa, approximately $60 \%$ of the 1.25 billion people are below the age of 25 years (Niang, 2019). In Uganda, statistics are no different with an estimated $21 \%$ of the nation's population being youths. These statistics show the necessity of including the youths in the democratisation processes both at the global level as well as the national level.

A study conducted on the democratisation process of Uganda since its return to multiparty system explored perceptions held on the YPPs (Perrot, 2016). The participants brainstormed on the significance of involving the youths in LGCs; the overarching view which was dominant to every participant was 'very significant'. Also, in regarding this reaction, every view given was categorised along obtainable hypothetical assumptions for youth representation (Belschner, Garcia \& De Paredes, 2020:1). Whereas a small number of participants noted that the YPPs were not essential in taking care of the general interests of the youths, majority advocated that YPPs are a reasonable move. Nonetheless, other reactions looked at specific issues such as responsiveness of youth representatives to the unique challenges facing the youth, for example, structural unemployment (Mazorodze, 2020; Ndjié, Ondoa \& Tabi, 2019:872). This leads to the next issue of whether the youth representatives do represent the interests of different categories of youths.

\subsection{Representing the unique interests of the youths}

Discussions in favour of YPPs have resulted from the assertion that the youths representatives who share experiences and concerns of their colleague youths stand in a superior position of representing them unlike other classes of youths (Saud, 2020). For example, a rural based youth (worldwide) who has endured with the challenges of scarcity of virtually every public service ranging from basic education, basic healthcare, and basic infrastructure is better placed to represent and speak for what he or she has experienced and would love to see a better life for himself or herself and the constituency (Butler, 2020; Mngoma, Ayonride, Fergus, Jeeves \& Jolly, 2020). As a consequence, the youths are perceived to offer various thoughts, beliefs, priorities and styles emerging from their own environment, which is considered as essential in the youth political proportion (Mindzie, 2015). The YPPs are thus projected to advocate policy agendas that speak to exclusive concerns of the youths such as quality of education, unemployment, work-related challenges as well as collective welfare. In principle, nevertheless, the question of whether the YPPs epitomize the interests of the youths, obtainable literature reveals that the youths are a unique constituency in society who dominate the global population and are likely to endure. There are specific necessities, interests and concerns that emerge from the environment of the youths and these are inadequately addressed in policymaking that is controlled by others. Such specificities include employment-related sexual persecution, demand for several years of relevant work experience, and omission from a number of politico-economic spaces (Schwartz \& Yalbir, 2019).

According to Awad (2020:1), the socio-political benefits associated with YPPs suggest the consistency of youth representatives on concerns of favourable policies such as equal employment opportunities seeing that youth unemployment is surging. Welchman, Zambelli and Salil (2020) note that the colonial system of human resources management is an instrument aimed to exclude a number of youths from both joining the organisational ranks as well as ascending to the apex. By denying a 
proportionate membership of a particular group in policy making fora, the respective interests of that group, in making significant decisions are omitted_Belschner and Garcia de Paredes, 2020:1). This view suggests that the presence of YPPs on accounts of common characteristics as well as comparable experiences, can a long way in generating issues which attract deliberate policy consideration. For example, issues relating to youth interests were formed the bedrock of the insights held about the YPP in Uganda. In the agreed reactions, concerns of youth welfare were common amongst a number of participants. The experiences of the youths turned out to be a resounding entitlement for their likelihood of representing the concerns of colleague youths. While the reactions were diverse, the joint opinions were that the youths have specific concerns which call for proportional visibility seeing that none of the other representatives can put them forward; that the youth representatives can clarify and advocate for the rights of their constituency using the youth political proportion (Mejias \& Banaji, 2019:1714).

Majority of the participants were convinced that YPPs are necessary in matters of similar underprivileged groups such as children as they have no specific representation in both LGCs and the Parliament. These ideas are suggestive of the view that the youths are champions of their colleague youths unlike others and denotes a prospect of others' self-centred marginalisation of the youths' concerns once the youths are lacking in the political scene (Mejias \& Banaji, 2019:1714). The views more so point to the fact that the youths share common experiences and concerns symptomatic of shared aspirations that are competently epitomised by fellow youths. This suggests that youth councillors as well as youth members of Parliament represent opinions of the youths with regard to their existence both as a social category in policy making processes.

\section{Research methodology}

The key method used in this article was a desk review of obtainable literature on youth representation in Uganda and other parts of the world. Desk research essentially involves gathering of information from obtainable resources such as academic journals, the internet and publications. This is accompanied by cross-referencing as well as the organisation of such data. It has been recognised as a very effective method and can be conducted at any phase of a research project in the research process.

\section{Results and discussions}

\subsection{Contested issues on the youths as a social category}

Despite the fact that the perception of youths' interests appears at the front of YPPs, a wide array of essential issues have been put forth in the process of representation (Rothschild, 2020:1). These issues arise from the various social classes from which the youths representative originate and the characteristics of their publics since a number of them have for long been uninterested in politics, cynical of office-bearers and lee visible in representative institutions (Matthie, Vrydagh, Caluwaerts \& Erzeel, 2020:204). A twofold problem is visible: (a) assuming the youths belong to a special interest group, what interests are special to them that are represented and how can those interests be isolated from the general interests of the general electorate? (b) Assuming the youths are not a special interest group, what are they and how well can their unique concerns be represented? Sotiropoulos (2019:606) describes an interest group to be vehicles for expressing concerns as well as a symbol concerning the state, in a number of behaviours. Nevertheless Thomas (n.d) describes an interest group as "any association of individuals or organisations, usually formally organised, that, on the basis of one or more shared concerns, attempts to influence public policy in its favour".

An organised interest group is different from an unorganised interest group given that it is selfconfident and embraces most strong and established vigorous groups (Fouirnaies \& Hall, 2018). According to Scattaschneider special interest organisations are designed when to take care of small numbers of individuals who are cognisant of their special benefits (page 34). He perceives organised special interest groups as being set apart by a central component of being all-embracing, which suggests that they put a strong border detaching them from other groups. In same vein, Scattaschneider brings out issues of concerning the gap between special interests and public interests. He proposes that public interests denote to broad or collective interests common to all or by every 
member of the community, while special interests are benefits common to a small number of individuals or a section of the public; they do not include others and may become adversarial to them (page 23). He recognises that in a multifaceted community, there are benefits that are common to all members of the community and others which are not common to the community. He advises that while a community is composed of several interest groups, some groups embrace interests of a joint nature while others share specific interests with special nature of benefits for the individual group. Yet, it is necessary to take note of the intricacy of creating a superficial distinction between a special interest group and a public interest group as well as amongst an organised group and an unorganised group.

The observations raised on the subject of welfares and interest groups suggest a number of concerns on the Ugandan youth representation. We recognise that the competence of the Ugandan youths can neither meet the requirements of an organised group nor can they be regarded to be a special interest category. Like elsewhere, Ugandan youths cannot be treated as anonymous category with regard to class, faith, ethnicity, and any other known classifications. As a result of the intersection among the youth social classifications, the youth group turns out to be non-organised, saturated with various concerns of every social category. Besides, the youth's statistics give the impression of surpassing the degree of the imagined special interest groups. David and Buchanan (2020:10) reflects on the assumption that every youth shares the similar aspirations and objectives as being unacceptable. This assertion is not accurate on ground that the youth representatives are not restricted to any obligation of seeking out what the youth constituency desires; and for delegating representatives with illusory policy proposals (Ah Kwon, 2019:926). Indicators of other social researchers consider representing concerns of the youths as unachievable pointing to circumstances such as confidence and diversity among the youth category, while recognising the feasibility of capitalist youth representatives to embody such concerns (Lindbald \& Lundahl, 2020; Zukerfeld \& Wylie, 2017).

These observations thus propose an assumption that the concerns which are characterised as youths' interests are very challenging to demarcate from other concerns and can be perceived as community interests (Foundjem-Tita, Duguma, Speelman \& Piabou, 2018). As a consequence, it becomes the responsibility of the electorate to empower the youth political representatives and hold them liable for such interests if they are considered exceptional and constructive to the community that includes the youths.

\subsection{Controversies on the youths as a constituency}

Whereas the YPP remains saturated with enormous uncertainties, the subject of youth interests is, in addition, muddled by the characteristics of the youth electorates. As stated by McKelvey (2020), the contemporary Nation has introduced citizenship as an essential prerequisite for political representation in relation to the position of representation which never was in pre-contemporary consensuses. They suggest that citizenship has proved to be a time-tested historical consequence of political fairness by embracing multitudes of people in both national and local governance. While the opinion of political fairness based on territorial electorates is considerable, Hamilton (2018) suggests that geographical classifications is only one of possible means by which communities take part or become affected by collective arrangements and or choices. That study (by Hamilton) recognises the presence of numerous non-territorial concerns such as faith, traditions, patriotism, community engagements, and or individual characteristics that take into account non-territorial welfares. A separate study suggests the occurrence of additional territorial concerns such as immigration, international trade, and the environment (Shankley \& Byrne, 2020). These influences include transnational formal actors such as the Breton woods institutions and a mass of multinational engagements as well as the civil society each of which presenting representative entitlements and serving interests of representatives.

Arising from these community interest agendas, Robin (2019) analysed the conceptual controversies concerning whether representatives have a duty to represent electorates or interests of a community. They infer that in the contemporary legitimate egalitarianisms, there is a picture of electorates whose only commonality is a dwelling place. Nonetheless, much a dwelling-oriented elected representative takes account of a number of community classes inside the local communities, such individuals are 
simply samples in as far as this their principal concerns and characteristics are defined. In place of electoral constituencies defined on the foundation of characteristics such as race or faith, they are categorised as being represented on the assumption that they interconnect with conditions of locality, occasioning into secondary associations between representative autonomy and methods of representation (Van Veen, 2019). It is assumed that youth representatives derive influence from a number of elements with numerous interests which produces numerous legalities and insoluble democratic responsibility concerns. This is an obvious controversy in representing interests of the youths (Mhike, 2018). The challenge here is tangled with issues such as the comparative primacy of local concerns as opposed to nationwide concerns, the responsibility of political organisations and the characteristics of political actors. It becomes more complex also by the variances between representing a solitary constituency versus representing various political constituencies. But, the agendas presented by rival political organisations can never embrace the complete choice of pertinent of issues, it is necessary to follow extra methods of representation that embraces undetermined aspects.

The subject of electorates is vital when examining the two youth representatives (one male and one female) in the Ugandan local governments that are voted through electoral colleges to represent the youths at every level ranging from the village to the district (Zingher, 2016:233). These representatives obtain their influence from several principals even though they are expected to accommodate the welfares of the amorphous youth category. The nitty-gritty of the problem is that the youths are a portion of the communities and the manifold principals that they embody; and the interests of the community from which the youths gain is an equivalent obligation for the youth councillors.

\subsection{Controversies over interests of the youths in Uganda}

The outcomes on the subject of interests of the youths raised by participants during personal interviews reveals that concerns of interests of the youths present an enormous challenge to the youth councillors and or youth members of Parliament (Mpungose \& Monyae, 2018). During the study, several issues focusing on the youths as a challengeable general community group and the consequence of constituencies came up with a suggestion that there are standard difficulties of their representation procedure. Some views emphasised the method in which the youths in LGCs and or the Parliament are unsuccessful in advocating specific causes of the youths rather they are pushed to advocating concerns of the general community, the electorate that do not vote them (Berthin, 2014). Several other opinions looked at the youths demonstrating broad concerns instead of concerns affecting and or benefitting the youths. Similar views give emphasis to the fact that most community services are supplied on demand and so the other representatives emerge to call extra services than the youths. Thus far other participants viewed problems of the youths as being farfetched and too interlaced to be adequately advocated by two youth representatives in a big council or Parliament.

There were likewise observations linked to the degree of influence a political belief as well as government strategies have on specific policy proposals. These concerns put the youths in a tricky situation and with least influences for the intents to emphasis interests of the youths since either those concerns have been addressed in the strategic priorities of government or agendas of a political organisation (Bisson, 2020). Also, the tag for youth representatives in Uganda has attracted scores of uncertainties. For example, identifying such representatives as youth councillors or youth representatives lessens the prospects of clarification and accepting the connotation of the characteristic, the responsibility as well as resolve of those representatives (Zhang, 2011). The diverse tags placed onto the youth councillors and or youth members of Parliament suggest their remote description as well as functional representation. It likewise tells the density of demarcating interests of the youths for their constituencies. This reveals the difficulty of discriminating distinct interests from community interests and discloses that in several occasions, the interests to be embodied are attended to on piecemeal basis by government ministries. 


\subsection{Youth representation as an approach to good governance}

Youth representation is perceived as a demonstration of good governance especially the issue of increased participation and fairness (Grasso, Farall, gray, hay \& Jennings, 2019), excluding in Parliament and or LGC is perceived as a strategy aimed to isolate them. According to Loprest, Spaulding and Nightingale (2019), isolating the youths is a direct strategy to impede their movement to attaining parity. Loprest et al (2019) maintains that the youths are a community group the same way spiritual or racial groups are, as a consequence, a fair civilisation embraces the youths in its governmental debates. They perceive a genuine political system to adhere to the values that make a democracy and a different community groups become part of the government organisations (Webster, 2018). In Webster's observation of a democratic society is that it has a duty to provide strategies for effective acknowledgement and demonstration of the diverse opinions and views of those of its basic categories that are underprivileged. When that strategy fails then it is perceived to put forth policy proposals that maintain hegemony of the main groups (Shafqat, 2019) and such a situation cannot pass a democratic test. Elected societies are categorised by two values, namely; widespread control and fairness in government (Lind, 2018). Widespread control underscores direct involvement in processes of decision-making or enjoying regulation over those entrusted with making decisions which denotes capacity to hold them liable and receptive. Political fairness is associated with issues of equality in voting power, equal privileges and prospects to contest for a public office and equal circumstances permitted to put forth an opinion and be listened to. In his defence for values of democracy, McAllister and White (2015:79) underscores the principles of fairness and independence among humankind.

Repetitive declarations of youth representation focus on a few or each one of these principles as some of the outcomes for this study point out. As a democratic gesture, youth representation in Uganda was regarded as rational to the extent that their budding demographic statistics mandate attention to that constituency. Bearing in mind that in Uganda, the youths form approximately $60 \%$ of the entire population (Alava, 2018) and they are regarded as a strong pillar of both the informal economy and the small-scale economy. This stance was held by majority of participants regarding the worth of youth involvement in the Ugandan local and national political affairs. Much prominence was put to having youth representatives for guaranteeing both democratic and monetary responsibility. Voices of the youths were perceived to be loud on issues of accountability; there is a prospect of having a consistent set of voices which keep government on its toes when the youths are involved (Jjuuko \& Tabengwa, 2018). Since accountability is treated as a value of good governance, political presence of the youths in one way suggests good governance. Nonetheless, political presence of the youths is in a number of instances perceived as a calculated target for authenticating the government in the international democratic framework concerning the gesture for fairness in the community. This view advocates that the youth councillors and members of Parliament are adopted as symbolic representatives aimed at hoodwinking the global publics rather as a strategic means to emancipating the youth category.

\subsection{Insights on the Ugandan YPPs: an illustration}

This study interrogated the opinion of participants on whether they were opposed to raising or lowering the ratio of youths in LGCs and or national legislature. As regards their ratio in LGCs, of the 18 participants, 12 participants $(66.7 \%)$ suggested raising the ratio while 6 participants $(33.3 \%)$ held the view of preserving the status quo, that is, two youth representatives on every local government council. Of the $66.7 \%$ who proposed raising the ratio of the youth on the local government council, 8 participants backed $100 \%$ rise while 4 participants supported $25 \%$ of the political spaces to be set aside for the youths for both LGCs and the national legislature. None of the participants advocated a reduction or elimination of the youth representatives in the political circles. These figures expose the considerable support towards involving the youths in political spaces of Uganda as well as the realisation of the fact that the population of Uganda is dominated by the youths. The call for increased ratios of the youths ought to be embraced in political parties and organisations too and it should be maintained in the national Constitution of Uganda. 
Additional investigation into why the views showed that participants called for $100 \%$ rise noted that legislation should offer opportunities for more youths beyond the present two representatives on every local government council and five representatives in the national legislature. Also, due to the fact that a good number of youths cannot successfully contest in the mainstream political spaces seeing that much of the politics in Uganda have become commercialised where the wealthy others have greater means to reach and induce a number of voters and hence more opportunities of being elected. Other participants revealed that having $20 \%$ representation at all levels of every political party is fitting since political parties are considered to be one of the key training grounds for political leadership. Other participants supporting $20 \%$ youth representation maintained that it is a reasonable platform for the youths building on their past political numbers.

For those participants that backed $100 \%$ rise, their view focussed on the fundamental subject of agebased disparity with assertions of the youths being the main stream of the population in Uganda. The central recommendation was that politics have to be balanced in numbers and judgement of every category, including the youths. Having a handful of youths in the governmental policy making forums relegates them to dearth of ability to have an influence on the direction of policy debates. Other participants revealed that the youths continue to offer a lot of support to the government; right from the Military as well as the Police and therefore the government ought to reciprocate by appreciating their energies by rising their numbers at significant forums. Likewise, the participants revealed that the move, by the government of Uganda, to introduce special representatives for the elderly when a number of others occupying the political spaces are the elderly was a ridicule to the youth community. Linked to the critical mass philosophy, other participants maintained that the youths are determined to facilitate the country to achieve much once their numbers in politics are increased.

To attain an age-based political equilibrium in terms of numbers, participants proposed a threemember electorate representation; that is, one man, one woman and one youth. As suggested, participants recommended that the three-member model would ease the challenge of gerrymandering which has led to an over-bloated national legislature. To others, preserving the status quo was a better move on grounds that regardless of having a small number of youths in LGCs and the National Legislature, merely not many of them made direct contributions that aim to benefit the youth constituency during debates. As a result, the legal framework was giving preference to the youths to compromise the political base on which they can contest without scaffoldings quoting deliberate policies such as universal education as well as equal employment opportunities. They sustained that the present ratio was satisfactory and for the remaining political prospects, the youths should race with others. Consequently, an additional rise in the ratio of the youths means downgrading others given that the number of youths would supplant all other representatives in the medium-term. A separate view revealed that raising the ratio of the youths suggests demoting other groups whose competences of political competition are unparalleled to a number of youths who would make it due to enlarged ratios.

\subsection{Implication of critical groups in political representation}

This study has exposed several concerns pertaining to political representation of the youths. It has revealed that the issue of youth representation is understood as essential for addressing interests of the youths but likewise for the principles of good governance. The opinion for interests of the youths demonstrates that the youths face comparable experiences and similar interests and have ability to represent their interests better than others. Other propositions also stress representation capabilities of some youth compared to men and women suggesting that given political opportunity, the youths may perform political roles sufficiently especially in matters that concern them and the country as a whole. These views suggest that youth reps can be perceived as being capable of acting for the youths.

The good governance values hold that the presence of the youths is essential as an issue of fairness seeing their demographic ratio and their role to the state and the economy in general. Such ideas furthermore look at the political presence of the youths as representative and significant as well as an issue of Human Rights, responsibility and receptiveness. These observations describe youth representation as expressive and depictive suggesting their delegated nature of representation but 
likewise propose the principal-agent representation when we look at aspects of their individual liability and responsiveness. Statistically, it is noted that there is undisputed desire for increased presence of youths in politics. Attitudes about youth ratios revealed massive support for more seats to be set aside on two assertions, viz; the persistent obstacles that restrict them from favourable competition with others, and their huge constituency. Views pertaining to persistent obstacles to the youth's representation advocate a potential effect of polarity that underscores differences based on culture.

The notion of youth big electorate can be considered as a scheme put forth by others so as to polarise the youths given that others perceive themselves as the central political group. This move is likewise meant to discourage the political desires of the youths. Consequently, this study suggests that the youth constituency was premeditated without consulting the target group. The constitutional provision for two and five representatives on every local government council and the national legislature has reduced prospects for embracing the youths who have an option of associating against being prejudiced by the others. The alternate scheme for the others has been to shift the political goal-post during party primaries knowing that individual youths will be challenged and portrayed as incapable candidates. The electoral dynamics subject the youth to conspicuousness and they end up underperforming as a consequence of the muzzled electoral conditions for representatives. For example, the ruling National Resistance Movement (NRM) party decided to move away from the secret ballot to the obsolete system of lining behind the candidate or agent or poster during the 2020 party primaries for every elective office. As a result, a number of candidates, the youths inclusive, were outrigged by the others who were not willing to bow out of power.

In this view, arguments for age-based parity or increased proportions appear practical in the political field of Uganda. Also, as noted earlier, the youth numbers may be admissible seeing their ratio to the overall population as well as their contribution in the overall economy is insurmountable. This study recognises that the approval within the population about the ratio of the youth proportions vis-à-vis two representatives, is not close to the proposed parity ratio of $25 \%$. Looking at the two representatives, the current total number of youths in the LGCs stand at an average of $38 \%$, which is an approval for increasing their proportion on account of objectivity. When locus is made to the representatives, the idea of youth representation in LGCs is classifiable as a non-balanced proportion and so the call for increased proportions, in this case, desires attention.

The general observation of Uganda youth proportions at the LG level appears to show that increased numbers is a fair play. As noted by Sanusi and Nassuna (2017), Uganda proportions are a strategy for reimbursing for the obstacles limiting the formerly disadvantaged sections as well as an incentive for their role in the political scene and the economy as a whole. This proposal is envisioned to accomplish some level of age-based parity at least in political statistics which is a component of good governance. Per se, the proposal can be considered to match with visibility representation. The problem of the practical role of youth representatives, nonetheless, swings in balance as it appears that what is represented is reliant on various significant stakeholders whose demands are very dynamic.

\section{Conclusion}

This article has discussed the relevance of proportions of youth representatives in the governance of Uganda. The study examined opinions supportive of youth representative proportions and the methods in which the proportions are achieved. The outcomes concludes that while the political interests often treated as youth interests, they are a challenge and separating them from the public interests is puzzling. Further, the study concludes that proportions are a means of reimbursing for obstacles against the youths as well as an incentive towards their role in both politics and the national economy. As a consequence, the relevance of youth functional roles remains unattached in nature since what is represented is contingent upon diverse participants whose interests are not immobile. 


\section{Limitation and way forward}

This study basically covers Uganda and so the outcomes may not simply be generalised in other countries whose political environments are different from that of Uganda.

\section{References}

Alava, H. (2018). Acholi youth are lost: young, christian and (A)political in Uganda. In Oinas, E., Onodera, H., and Suurpaa, L (Eds.). What politics?: youth and political engagement in Africa (pp. 246-264). Leiden: Boston: Brill. Retrieved October 23, 2020 from http://www.jstor.org/stable/10.1163/j.ctvbqs5zx.16

Awad, A. (2020). From school to employment; the dilemma of youth in Sub-Saharan Africa. International Journal of Adolescence and Youth, Accessed DOI: 10.1080/02673843.2020.1778492.

Belschner, J., and Garcia de Paredes, M. (2020). Hierarchies of representation: the re-distributive effects of gender and youth quotas. Representation. Accessed DOI: 10.1080/00344893.2020.1778510.

Berthin, G. (2014). Youth political participation in local governments: initial evidence from Latin America. Social and Economic Studies, 63(3/4). 107-42. Retrieved October 23, 2020, from http://www.jstor.org/stable/44732888

Bieber, I., and wingerter, L. (2020). Is it all a question of the electoral system? The effects of electoral system types on the representation of women in German municipal councils. German politics. Accessed DOI:1080/09644008.2019.1707189

Bisson, L. (2020). (Rep.). Clingendael Institute. Accessed DOI: 10.2307/resrep24643.

Butler, R. (2020). Youth, mobilities and multi-cultures in the rural Anglosphere: positioning a research agenda. Ethnic and Racial Studies. Accessed DOI: 1080/01419870.2020.1730927.

Dahlerup, D. (2005). Strategies to enhance women's political representation in different electoral systems. Paper presented at the conference "Women Shaping Democracy". Progressive politics ten years after the World Conference on Women in Beijing. Manila, Philippines, 24-25 October 2005.

David, N.P., and Buchanan, A. (2020). Planning our future: institutionalising youth participation in local government planning efforts. Planning Theory \& Practice, 21(1), 9-38.

Fouirnaies, A., and Hall, A. (2018). How do interest groups seek access to committees? American Journal of Political Science, 62(1), 132-47.

Foundjem-Tita, D., Duguma, L., Speelman, S., and Piabou, S. (2018). Viability of community forests as social enterprises: a Cameroon case study. Ecology and Society, 23(4). Accessed DOI: $10.2307 / 26796883$.

Franzmann, S.T. (2019). Extra-Parliamentary opposition within a transforming political space: The AfD and FDP under Merkel III between 2013 and 2017. German Politics, 28(3). 332-49.

Goodfellow, T. (2017). 'Double capture' and de-democratisation: Interest group politics and Uganda's 'Transport mafia'. The Journal of Development Studies, 53(10). 1568-83.

Government of Uganda, (1997). The local governments Act. Uganda printing press corporation, Entebbe.

Government of Uganda. (1995). Constitution of the Republic of Uganda. Uganda printing press company, Entebbe.

Grasso, M.T., Farrall, S., Gray, E., Hay, C., and Jennings, W. (2019). Socialisation and generational political trajectories: an age, period and cohort analysis of political participation in Britain. Journal of Elections, Public Opinion and Parties, 29(2), 199-221.

Hamilton, M. (2018). Understanding what shapes varying perceptions of the procedural fairness of transboundary environmental decision-making processes. Ecology and Society, 23(4). Accessed: $10.2307 / 26796881$.

Jjuuko, A., and Tanegwa, M. (2018). 'Expanded criminalisation of consensual same-sex relations in Africa: contextualising recent developments'. In Jjuuko, A., Nicol, N., Lusimbo, R., Mule, N., Ursel, S., Wahab, A., et al. (Eds.), Envisioning global LGBT human rights: (Neo)colonialism, neoliberalism, resistance and hope (pp.63-96). London: University of London Press. Accessed DOI:10.2307/j.ctv5132j6.10 
Kadaga, R.A. (2013). Paper presented by the speaker of the Ugandan parliament at the commonwealth secretariat during the tenth commonwealth women's affairs ministers meeting (10WAMM) in Dhaka, Bangladesh 17-19 June.

Kassman, A., and Vamstad, J. (2019). Local public administration as facilitator of political youth participation - good intentions and institutional shortcomings. International Review of Sociology, 29(3), 484-97.

Kwon, S. A. (2019). The politics of global youth participation. Journal of Youth Studies, 22(7), 92640.

Lebon, I., Baujard, A., Gavrel, F., Igersheim, H., and Laslier, J. (2018). 'Sincere voting: a laboratory experiment using alternative proportional systems'. In Stephenson, L., Aldrich, J., and Blais, A. (Eds.). The many faces of strategic voting: tactical behaviour in electoral systems around the world (pp. 203-32). Ann Arbor: University of Michigan Press. Accessed DOI:10.2307/j.ctvh4zhzr.13.

Lind, E. (2018). 'Transparency, trust and public value'. In Wanna, J., and Vincent, S. (Eds.). Opening government: transparency and engagement in the information age (pp.87-106). Australia: ANU Press. Retrieved October 23, 2020, from http://www.jstor.org/stable/j.ctv1rmjnq.12

Lindblad, M., and Lundahl, L. (2020). Winding paths through school and after-young swedes of migrant origin who failed in upper secondary school. In Lundahl, L. and Brunila, K. (Eds.). Youth on the move: tendencies and tensions in youth policies and practices (pp.79-100). Helsinki University press. Accessed DOI:10.2307/j.ctvx8b70v.7

Loprest, P., Spaulding, S., and Nightingale, D. (2019). Disconnected young adults: increasing engagement and opportunity. RSF: The Russell Sage Foundation Journal of The Social Sciences, 5(5), 221-43. DOI:10.7758/rsf.2019.5.5.11.

Matthieu, J., Vrydagh, J., Caluwaerts, D., and Erzeel, S. (2020). The democratic credential of youth parliaments. The case of the Belgian Jeugd Parlement Jeunesse. The journal of legislative studies, 26(2). 204-22.

Mazonrodze, B.T. (2020). Youth unemployment and murder crimes in KwaZulu-Natal, South Africa. Cogent economics \& finance, 8(1).

McAllister, A., and White, S. (2015). Electoral integrity and support for democracy in Belarus, Russia, and Ukraine. Journal of Elections, Public Opinion and Parties, 25(1). 78-96.

McKelvey, S. (2020). Unstate: disarticulating state knowledge and Joan Didion's democracy. Journal of Modern Literature, 43(3), 116-31. Accessed: DOI: 10.2979/jmodelite.43.3.07.

Mejias, S., and Banaji, S. (2019). Backed into a corner: challenging media and policy representations of youth citizenship in the UK. Information, Communication \& Society, 22(12). 1714-32.

Mhike, I. (2018). Political violence in Zimbabwe's national youth service, 2001-2007'. In Oinas, E., Onodera, H., and Suurpáá, L (Eds.). What politics?: youth and political engagement in Africa (pp. 246-264). Leiden: Boston: Brill. Retrieved October 23, 2020 from http://www.jstor.org/stable/10.1163/j.ctvbqs5zx.21

Mindzie, M. (2015). Building peace and development in the Sahel: enhancing the political participation of women and youth (Jpp. 2-3, Rep.). International Peace Institute. Retrieved October 23, 2020, from http://www.jstor.org/stable/resrep09525.4

Mngoma, N.F., Ayonrinde, O.A., Fergus, S., Jeeves, A.H., and Jolly, R.J. (2020). Distress, desperation and despair: anxiety, depression and suicidality among rural South African youth. International Review of Psychiatry. Accessed DOI: 1080/09540261.20201741846.

Mpungose, L., and Monyae, L. (2018). (Rep.). South African institute of international affairs. Accessed DOI: 10.2307/resrep25985.

Mugisha, M., Ojok, D., Kiranda, Y., and Kabasa, B.B. (2016). Youth participation in political processes in Uganda: exploring opportunities and constraints. Perspectives of African democracy \& development, 1(1).

Mwesigwa, D., and Mubangizi, B.C. (2019). Contributions of the Youth Livelihood Programme (YLP) to youth empowerment in Hoima district, Uganda. International journal of business and management studies, 11(1), 54-71.

Ndjié, A.A., Ondoa, H.A., and Tabi, H.N. (2019). Governance and youth unemployment in Africa. Labour History, 60(6), 869-82. 
Niang, T. (2019). Raising the voice of young people in governance. Wednesday March 6. Retrieved on 2-11-2020 from https://www.brookings.edu/research/governance-lags-behind-youthexpectations-and-needs

Okedele, A. (2020). Women, quotas, and affirmative action policies in Africa. In Yacob-Haliso, O., and Falola, T. (Eds.). The Palgrave handbook of African women's studies. Palgrave Macmillan, Cham. Accessed: https://doi.org/10.1007/978-3-319-77030-7_80-1

Otite, A., and Ohwona, A.I. (2010). The changing political role of youths in oil producing areas of Delta state. Journal of Social Sciences, 24(3).183-88.

Perrot, S. (2016). Partisan defections in contemporary Uganda: the micro-dynamics of hegemonic party-building. Journal of Eastern African Studies, 10(4), 713-28.

Robin, G. (2019). Our decomposing democracy. AQ: Australian Quarterly. 90(2). 33-9.

Rothschild, J.E. (2020). Identities, interest group coalitions, and intergroup relations. Politics, groups, and identities. Accessed DOI: 10.1080/21565503.2020.1756358

Sanusi, I., and Nassuna, R. (2017). (Rep.). South African institute of international affairs. Accessed DOI: $10.2307 /$ resrep25939.

Saud, M. (2020). Youth participation in political activities: the art of participation in Bhakkar, Punjab Pakistan. Journal of Human Behaviour in the Social Environment. 30(6). 760-77.

Schwartz, M., and Yalbir, N. (2019). (Rep.). Global centre on cooperative security. Accessed DOI: 10.2307/resrep20330

Shafqat, S. (2019). Pakistan military: sustaining hegemony and constructing democracy? Journal of south Asian and Middle Eastern studies, 42(2), 20-51.

Shankley, W., and Byrne, B. (2020). 'Citizen Rights and immigration'. In Shankley, W., Byrne, B., Alexander, C., Khan, O., and Nazro, J. (Eds.). Ethnicity and race in the UK: state of the nation (pp. 35-50). Bristol, UK: Chicago, IL, USA: Bristol University press. Accessed: $10.2307 /$ j.ctv $14 \mathrm{t} 47 \mathrm{tm} .8$

Sotiropoulos, D.A. (2019). Political party-interest group linkages in Greece before and after the onset of the economic crisis. Mediterranean politics, 24(5), 605-25.

Thomas, C.S. (n.d). Interest group. University of Alaska southeast, Juneau.

Van Veen, A. (2019). Regulation without representation? Independent regulatory authorities and representative claim-making in the Netherlands, 1997-now. In Kaal, H., and Slootjes, D. (Eds.). New perspectives on power and political representation from ancient history to the present day: repertoires of representation (pp.171-202). Leiden: Boston. DOI: 10.1163/j.ctvrxk3p3.15.

Webster, N. (2018). (Rep.). Danish institute for international studies. Accessed DOI: 2307/resrep21347.

Weinmann, P., and Grotz, F. (2020). Reconciling parliamentary size with personalised proportional representation? Frontiers of electoral reform for the German bundestag. German Politics, Accessed DOI:10.1080/09644008.2020.1790531.

Welchman, L., Zambelli, E., and Salih, R. (2020). Rethinking justice beyond human rights. Anticolonialism and intersectionality in the politics of the Palestinian youth movement. Mediterranean Politics. Accessed DOI: 10.1080/13629395.2020.1749811.

Zhang, B. (2011). Democratizing Hong Kong: Functional representation and politics of institutional change. Pacific Affairs, 84(4).643-64. Retrieved October 23, 2020, from http://www.jstor.org/stable/23056126

Zingher, J. (2016). The relationship between bias and swing ratio in the Electoral College and the outcome of presidential elections. Journal of Elections, Public Opinion and Parties, 26(2), 23252.

Zukerfeld, M., and Wylie, S. (2017). Capitalist exploitation. In knowledge in the age of digital capitalism: an introduction to cognitive materialism (pp. 115-60). London: university of Westminster press. Retrieved October 3, 2020, from http://www.jstor.org/stable/j.ctv6zd9v0.9. 